\title{
TWO YEARS EXPERIENCE WITH DIPHENYLTHIOUREA (DPT Or CIBA 1906) IN THE TREATMENT OF LEPROSY
}

\author{
by J. M. B. GARROD, M.B., B.Ch., B.A.O., D.T.M. \& H. \\ Director, East African Leprosy Research Centre, Alupe, Kenya
}

\section{Introduction}

One of the drawbacks to the use of the sulphones in leprosy is that reactions are increased in number and severity. At the best these are troublesome and interrupt treatment. They can cause serious constitutional disturbances and are hardly beneficial to the patient if the more severe types develop. Severe cases may only be kept in tolerable comfort by continuous administration of corticosteroids. Diphenylthiourea (DPT) was reported to be active in leprosy by Davey and Currie' (1956) and by Ross Innes et al.2 (1957). A further report by Davey et al. ${ }^{3}$ (1958) confirmed the earlier report, and drew attention to the lesser incidence of reactions among patients treated with DPT. Further experience here with some of the patients reported by Ross Innes and some additional patients up to April 1959 is recorded here.

\section{Patients}

All were inpatients of whom four had had substantial previous treatment with DDS. All others denied previous treatment, or admitted to receiving only a few tablets of DDS beforehand at outpatient dispensaries and health centres where oral DDS is generally available. Forty patients were studied and their numbers and types are shewn in Table I. The distribution of cases bears no relation to the general incidence but is more an indication of the types seeking inpatient treatment.

TABLE I

$\begin{array}{lcccc} & \text { Tuherculoid } & \text { Lepromatous } & \text { Borderline } & \text { Indeterm. } \\ \text { Male Adult } & 10 & 11 & 2 & 0 \\ \text { Female Adult } & 3 & 5 & 0 & 1 \\ \text { Male under 18 } & 3 & 1 & 0 & 1 \\ \text { Female under 18 } & 1 & 1 & 0 & 1 \\ & 17 & - & - & 3\end{array}$

Lepromin tests were done on all patients before starting treatment. The lepromin used was a crude Mitsuda-Hayashi type prepared here. The lepromatous cases except three had negative Mitsuda tests. The three had doubtful tests with reactions less than $3 \mathrm{~mm}$. in diameter. Biopsies were taken before starting treatment. Histologically not all might have been accepted as lepromatous but they were 
what is known as frank lepromatous cases in Africa. Nodules were generally present, and bacilli were found easily in globi and in masses.

The tuberculoid cases had positive Mitsuda tests. Clinical photographs were taken at the start of treatment, and reference was made to them to refresh the memory.

Twenty-three inpatients on standard treatment were followed as controls for the bacilliferous cases. One male lepromatous case has been on both treatments, 17 months on standard treatment, and 12 months on DPT. The numbers and types of those on standard treatment are shewn in Table 2. There were no tuberculoid cases in this group.

\section{TABLE 2}

$\begin{array}{lccc} & \text { Lepromatous } & \text { Borderline } & \text { Indeterm. } \\ \text { Male Adult } & 11 & 1 & 0 \\ \text { Female Adult } & 8 & 1 & 0 \\ \text { Male under } 18 & 1 & 0 & 1 \\ & 20 & - & -1\end{array}$

Seventeen patients discharged themselves; six had no visible lesions; one was indeterminate, the other five were tuberculoid. The other 11 left for various personal reasons. All intended to get standard treatment at their homes.

\section{Methods}

At first liver and kidney function tests were done frequently. Red and white cell counts, haemoglobin estimations, and weight records were done monthly. Later when the absence of toxic effects was apparent, only haemoglobin and weight were recorded monthly. Smears were taken in alternate months of the bacterially positive cases. Smears of negative cases were taken every six months. Smears were taken from six sites, their positivity estimated as $0,1,2,3$, or 4 and the average calculated as a Bacillary Index (B.I.) Absence of patients on home leave has interfered with legular timing of the above, but has not affected the overall picture.

\section{Results}

The average initial B.I. for those lepromatous patients on DPT was 3.2, after 12 months 2.0 , and after 24 months 1.6. For those on standard treatment the figures are 2.7, 2.0, and 1.3. Expressed as percentages of the initial B.I. for comparison the figures are for DPT 100, 62.5, and 50; for standard treatment 100, 74, and 48. Figures for bacterial indices supplied by the M.O. in charge of the leprosarium and calculated on a comparable basis, show that for all lepromatous patients on standard treatment in the leprosarium the percentages 
are 100, 76, and 50. For the first twelve months the advantage lies with DPT. Clinical impressions support this. At first lesions resolve quicker on DPT than on standard treatment. Later progress slows. All patients on DPT have improved clinically. Tuberculoid and indeterminate cases have reacted to DPT in a manner similar to that expected on standard treatment. Nerve reactions have occurred but not tuberculoid reactions. One female tuberculoid patient has been discharged cured after 32 months treatment, having shewn no signs of activity for the previous year.

Among the more expensive and troublesome items of leprosy treatment is the necessity to provide ward accommodation for various reasons. The figures for the total treatment in months for those on DPT and on standard treatment were added up separately. The times spent in the wards, for whatever reasons, were also added up for each treatment, and the figures compared. Those on standard treatment total 400 months treatment with 926 days in the wards. Those on DPT, excluding tuberculoid cases, total 642 months treatment and 569 days in the wards. The time spent in the wards by those on DPT is considerably less than by those on standard treatment. For tuberculoid cases on DPT the treatment time is 368 months with 262 days in the ward, to which one patient alone contributed 129 days because of a foot ulcer. Part of the difference in favour of the DPT cases may be because reactions with DPT are milder and seldom require treatment. Seldom is there any need to interrupt treatment with DPT because of reactions. In only three cases was the dosage of DPT halved because reactions were difficult to control. Possibly this is the reason for the superiority of DPT in the first year, as it is then that patients are most in need of extra treatment for concomitant illnesses, and appear most likely to react. DDS is known to have a prophylactic effect against malaria (Leiker $\left.{ }^{4}, 1956\right)$. DPT apparently has no such effect as patients on it have been ill with malaria, and it is in spite of this that the ward time is better with DPT. Some of our patients here come from non-malarial areas and have no premunity.

\section{Histology}

In lepromatous cases biopsies show improvement after six months. Areas of infiltration grow less and become discrete. Round cells increase and fibrocytes appear. Bacillary densities are not much reduced in the early stages, but the absolute numbers are reduced because only rarely does a decrease in the area of infiltration cause an increase in the bacillary density. Ridley's Biological Index $x^{5}$ (1958) has been estimated for those patients on DPT and those on standard treatment. The average drop is $41 \%$ for those on DPT and $45 \%$ for those on standard treatment every six months. In tuberculoid cases 
the area of infiltration lessens, giant cells disappear, and fibrocytes appear in six to 12 months.

\section{Dosage and Toxicity}

The daily dosage of DPT was based on a rate of $50 \mathrm{mgm} . / \mathrm{kg}$. giving a dosage of 1.5 to $4 \mathrm{~g}$. daily. A special group of 10 patients was put on double dosage. Seven have received this higher dosage for two years; the other three discharged themselves. There were no toxic effects.

Mention must be made of the death of one patient from an acute anaemia of undiagnosed cause. The anaemia developed after he received $4 \mathrm{~g}$. of DPT over seven days. Unless one accepts an acute sensitivity it seems unlikely that the drug was the cause of death.

Fifteen patients had abnormal liver function as judged by thymol turbidity and bromsulphthalein tests at the start of treatment; seven of these became normal in one year. Four patients who had abnormal renal function tests became normal. There was no interference with the action of drugs commonly employed for treatment of the common local infections and infestations. Absorption and excretion studies here (to be published later) suggest dosage more than once a day would give best results.

\section{Special Cases}

Certain cases justify individual mention. They illustrate how DPT can be given to cases liable to reaction;

Case No. 3. A male lepromatous patient who had been on standard treatment for several years became unstable and reacted easily. From December, 1956April, 1958, that is after 17 months of standard treatment, his case card reads "on verge of reaction most of the time". Most of this time he had to be warded, and was on cortisone. His B.I. fell from 2.75 to 2 during this period. In May, 1958 he was put on DPT working up to a full dosage of $2.5 \mathrm{~g}$. daily by mid-July. By the end of July his reaction had stopped and cortisone had been stopped. He had occasional reactions up till October, 1958, since when he has been free from E.N.L. His B.I. has dropped from 2.0 to 1.2 in 12 months. He states that he is now free of the former continuous pain.

Case No. 4. A male lepromatous patient had had sulphones for four years with frequent reactions, and spent much of his time in the ward. He was put on DPT. His reactions continued for 11 months but were mild, and he remained ambulant except for a total of 12 days. For various periods totalling six months the dosage of DPT was halved. His B.I. has fallen from 1.7 and he achieves an occasional negative now.

Case No. 5. A tuberculoid male patient had reached that stage of no progress after 25 months on DDS. He improved during six months DPT then became stationary again. After 30 months DPT he has again started to improve. He has a persistent ulcer on his heel which may be the reason for his slow recovery.

Case No. 39. A lepromatous male patient had relapsed after insufficient standard treatment ending seven months previously. His progress on DPT has not been substantially different from what one would expect.

Case No. 38. A lepromatous male discharged himself against advice after 26 months treatment with only two months in which reactions were noted. DDS at an outpatient dispensary keeps him in continuous reaction.

Case No. 11. A female lepromatous patient was admitted in reaction. She was started on a full dose of DPT (3.0 g. daily) with no ill effects. 


\section{Summary}

DPT has shewn itself to have a curative effect in leprosy of an order similar to that of sulphones. Its cost is high and a daily dose is needed. Reactions are less, especially in cases which react easily. Reactions are generally mild and easily controlled and interruption of dosage because of reactions is generally unnecessary. This enables continuous effective treatment to be kept up. It has been free from toxic effects. DPT has been found to be useful in cases resistant to the standard treatment.

\section{Acknowledgments}

Thanks are due to the following persons who have assisted: E. J. Bishop, G. Ellard, J. Obwa, J. Opio, R. Rhodes-Jones, M. Smith, and to the leprosarium staff for co-operation in the work, and also to the patients for willing submission to troublesome and at times painful procedures.

Thanks are expressed to Messrs. Ciba Ltd. for generous supplies of tablets and helpful advice and assistance.

Thanks are expressed to the Administrator, East Africa High Commission, for permission to publish and also to BELRA for financial assistance.

\section{References}

1. Davey, T. F. and Currie, G. Leprosy Review, 27, 94, 1956.

2. INNES, J. Ross, et al. East African Medical Journal, 34, 395, 1957.

3. Davey, T. F. et al. Leprosy Review, 29, 25, 1958.

4. LeIKER, D. L. Leprosy Review, 27,66, 1956.

5. Ridley, D. S. Leprosy Review, 29, 45, 1958. 